Research Article

Lingbao Kong, Yanjun Zhou*, Kexing Song*, David Hui, Hao Hu, Baojiang Guo, Junwei Kang, Cunli Feng, and Jun Cao

\title{
Effect of aging on properties and nanoscale precipitates of $\mathrm{Cu}-\mathrm{Ag}-\mathrm{Cr}$ alloy
}

https://doi.org/10.1515/ntrev-2020-0007

Received Dec 2, 2019; accepted Jan 9, 2020

Abstract: In this paper, the $\mathrm{Cu}-0.52 \mathrm{Ag}-0.22 \mathrm{Cr}$ alloy was prepared by hot horizontal continuous casting. The effects of aging process on micro-hardness, electrical conductivity, and nanoscale precipitates of $\mathrm{Cu}-0.52 \mathrm{Ag}-0.22 \mathrm{Cr}$ alloy were studied. The electrical conductivity and micro-hardness increase significantly in the early aging time. With the extension of aging time, the electrical conductivity is basically unchanged and remains at a high level. While, the micro-hardness increases slowly, the change trend is different at $623 \mathrm{~K}, 723 \mathrm{~K}$, and $773 \mathrm{~K}$. The optimisation of process parameters occurs in $723 \mathrm{~K}$ for $2 \mathrm{~h}$. At this time, the electric conductivity is $95.8 \%$ IACS and the hardness is 104.1 HV0.1. The XRD result shows that the Ag and $\mathrm{Cr}$ are precipitated in elemental form copper matrix. Further TEM shows that, $\mathrm{Cr}$ exists at the sub-boundary in the form of larger nanoscale precipitates $(100-200 \mathrm{~nm})$. While a large number of Ag nanoscale precipitates $(8-10 \mathrm{~nm})$ is dispersed on the copper matrix. The synergistic effect of $\mathrm{Ag}$ and $\mathrm{Cr}$ nanoscale precipitates significantly improved the properties of the alloy.

Keywords: $\mathrm{Cu}-\mathrm{Ag}$-Cr alloy, aging, micro-hardness, electrical conductivity, nanoscale precipitates

${ }^{\star}$ Corresponding Author: Yanjun Zhou: College of Material Science and Engineering, Henan University of Science and Technology, Luoyang 471023, China; Collaborative Innovation Center of Nonferrous Metals, Henan Province, Luoyang 471023, China; Email: dazhou456@163.com

^Corresponding Author: Kexing Song: College of Material Science and Engineering, Henan University of Science and Technology, Luoyang 471023, China; Collaborative Innovation Center of Nonferrous Metals, Henan Province, Luoyang 471023, China; Email: kxsong@haust.edu.cn

Lingbao Kong, Baojiang Guo, Junwei Kang: College of Material Science and Engineering, Henan University of Science and Technology, Luoyang 471023, China

David Hui: University of New Orleans, Department of Mechanical Engineering, New Orleans, LA70148, United States of America Hao Hu: College of Material Science and Engineering, Henan University of Science and Technology, Luoyang 471023, China; Collab-

\section{Introduction}

Multi-component $\mathrm{Cu}$-based alloys have been explored as important functional materials for industrial application owing to their high strength, controllable micro-hardness and superior electrical conductivity. Sometimes they can also be used as bacteriostatic biomaterials [1-8]. Microalloying is usually used by material researchers to maintain the alloy's high electric conductivity and mechanical properties $[9,10]$. The high strength of alloys is due to nanoscale precipitates in the copper matrix during the aging process. The high electrical conductivity results from the low solid solubility of alloying elements [11-18, 25]. Krishna et al. [13] found that the presence of nanoscale precipitates in the soft matrix significantly improves the strength by resistance the motion of dislocations in the aging process of $\mathrm{Cu}-3 \mathrm{Ag}-\mathrm{Zr}$ alloy. The size of the $\mathrm{Ag}$ and $\mathrm{Zr}$ nanoscale precipitates was measured to be $7 \mathrm{~nm}$ and 80 $\mathrm{nm}$, respectively. By analyzing the results, they found that the major contribution to strength was form coherency and dislocation strengthening of nanoscale precipitates. Nanoscale precipitates were found through the research Precipitation behavior and properties of aged $\mathrm{Cu}-0.23 \mathrm{Be}-$ $0.84 \mathrm{Co}$ alloy by Zhou et al. [14]. A coherent nanometer precipitation results with the best strengthening effect. Peng et al. [15] pointed out that the morphology and phase relationship of nanoscale precipitates change with the aging process, having a great influence on the properties of the alloy. The above results indicate that the properties of the alloy depend on the morphology, distribution of the precipitated phase, and the relationship of phase relations. Moreover, both $\mathrm{Ag}$ and $\mathrm{Cr}$ are nanoscale precipitates.

$\mathrm{Cu}-\mathrm{Ag}$-Cr alloy as an extremely important $\mathrm{Cu}$-based alloy with obvious aging strengthening effect and good

orative Innovation Center of Nonferrous Metals, Henan Province, Luoyang 471023, China

Cunli Feng: Henan Senger Materials Technology Co., Ltd., Jiaozuo 454010, China

Jun Cao: School of Mechanical Engineering, Henan Polytechnic University, Jiaozuo 454000, China

๑ Open Access. () 2020 L. Kong et al., published by De Gruyter. (Cc) BY This work is licensed under the Creative Commons Attribution 4.0 License 
comprehensive mechanical properties [19-28], is known as a "pearl" because of its widely application in electrified railway contact lines, high fidelity video, and audio lines. When $\mathrm{Ag}$ and $\mathrm{Cr}$ are used as nanoscale precipitates of copper alloy, what is the effect on the properties of the alloy. Jia et al. [29] prepared $\mathrm{Cu}-0.1 \mathrm{Ag}-0.3 \mathrm{Cr}$ alloy by using vacuum induction furnace, and studied the relationship between heat treatment process and performances. The performance of the obtained alloy was the best after aging for $4 \mathrm{~h}$ at $723 \mathrm{~K}$, with the electrical conductivity of $82 \%$ and the micro-hardness of $144 \mathrm{HV}$. At this point, the elemental $\mathrm{Cr}$ is present in the form of nanoscale sediments. The size of nanoscale precipitates is $6-7 \mathrm{~nm}$, and the dislocation cutting mechanism has a great influence on the microhardness and strength of the alloy. Therefore, the electrical conductivity increased significantly due to the fine and well dispersed nanoscale precipitates. These nanoscale precipitates are caused by the decomposition of supersaturated solid solution during aging. Liu et al. [30]. prepared $\mathrm{Cu}-\mathrm{Ag}$-Cr alloys by vacuum melting furnace. Through deformation heat treatment (the shape variable was 40\%), the electrical conductivity was close to $90 \%$ IACS after aging for $4 \mathrm{~h}$ at $753 \mathrm{~K}$. It is found that $\mathrm{Cr}$ nanoscale precipitates exist in the form of single substance after TTRT and have a certain phase relationship. But it is considered that trace Ag exists in the matrix in the form of solid soluble copper, which has not been explained and proved. Chen et al. [31] prepared $\mathrm{Cu}-\mathrm{Ag}-\mathrm{Cr}$ (Ce) alloy by means of medium frequency induction furnace and studied the microstructure of $\mathrm{Cu}-\mathrm{Cr}-\mathrm{Ag}$ alloy under different treatment conditions. The addition of Ce element makes the electric conductivity of the alloy reach $93 \pm 0.1 \%$ IACS after $4 \mathrm{~h}$ of insulation at $823 \mathrm{~K}$. Alloy grain refinement's is not an important factor affecting the properties of the alloy. Xu et al. [32] adopted medium frequency induction furnace. They found that the micro-hardness and electrical conductivity of the alloy increased with the increase of $\mathrm{Ag}$ content under different heat treatments, and the electrical conductivity reached to $83.2 \%$ IACS. With the addition of $\mathrm{Ag}$, $\mathrm{Cu}-\mathrm{Cr}$ alloys exhibit obvious solution strengthening and significantly depressed chain precipitation of $\mathrm{Cr}$ nanoscale precipitates. It was explained as the relationship between the amount of $\mathrm{Ag}$ and the improvement of mechanical properties. The above study presents a little aboutAg and focuses mainly on the impact of $\mathrm{Cr}$ on the properties of the alloy. It has good mechanical properties, but it presents high loses of electrical conductivity. Therefore, in order to obtain high strength and high electric conductivity alloy, it is more important to control the nanoscale precipitates of $\mathrm{Ag}$ and $\mathrm{Cr}$ and to play a synergistic role.
Therefore, in this work, a hot horizontal continuous casting was used to produce the new $\mathrm{Cu}-\mathrm{Ag}$-Cr alloy. Then, the effect of aging treatment on properties and nanoscale precipitates of $\mathrm{Cu}-\mathrm{Ag}$-Cr alloy was studied by optical, SEM, XRD, TEM, and property testing. Simultaneously, the optimum aging process parameters were determined within the scope of the experiment.

\section{Experimental procedure}

First a small piece of high purity $\mathrm{Cu}$ was melted with $\mathrm{Ag}$ and $\mathrm{Cr}$, respectively at $1473-1573 \mathrm{~K}$ in a $7 \mathrm{~kg}$ vacuum inductive furnace to obtain $\mathrm{Cu}-3.5 \mathrm{Ag}$ and $\mathrm{Cu}-1.0 \mathrm{Cr}$ intermediate alloys. Then, the intermediate alloys were added to the graphite crucible of hot horizontal continuous casting equipment. The $\mathrm{Cu}-0.52 \mathrm{Ag}-0.22 \mathrm{Cr}$ alloy bar $(\Phi=16 \mathrm{~mm})$ could be obtained. The continuous casting rate was 20 $\mathrm{mm} / \mathrm{min}$ and the temperature of the graphite crucible was maintained at 1423-1473 K.

The solid solution and aging process for the alloy was carried out in heat treatment furnace. Briefly, After the solid solution process operated under $1223 \mathrm{~K}$ for $1 \mathrm{~h}$, the asprepared alloy was aging at $673 \mathrm{~K}, 723 \mathrm{~K}$, and $773 \mathrm{~K}$ for $0.5 \mathrm{~h}$, $2 \mathrm{~h}, 4 \mathrm{~h}$, and $8 \mathrm{~h}$, respectively. The dimension of the specimen was $\Phi=16 \mathrm{~mm} \times(15-20) \mathrm{mm}$. The micro-hardness was measured on HVS-1000 digital micro-hardness tester with a load of $100 \mathrm{~g}$ and a loading time of $10 \mathrm{~s}$. Each measurement was repeated for 6 times and the g error is less than $10 \%$. The electric conductivity of the sample was measured using a Sigma 2008B1 digital eddy current metal conductometer. Each sample was tested for 5 times and the measurement error was less than $0.02 \%$ IACS. X-ray diffraction (XRD) was used to analyze the phase compositions of alloys obtained under different conditions. Morphologies of the alloys and the distribution of the precipitates in the copper matrix were observed by scanning electron microscopy (SEM) and the JEM2000 high resolution transmission electron microscopy (HRTEM).

\section{Results}

\subsection{Properties of the alloy}

Figure 1 shows the change of micro-hardness of the $\mathrm{Cu}$ $0.52 \mathrm{Ag}-0.22 \mathrm{Cr}$ alloy prepared at different aging temperatures for various times between $0 \mathrm{~h}$ and $8 \mathrm{~h}$. As shown in Figure 1, the micro-hardness of the alloy obtained after solid solution treatment is only 40.3 HV0.1, which greatly 


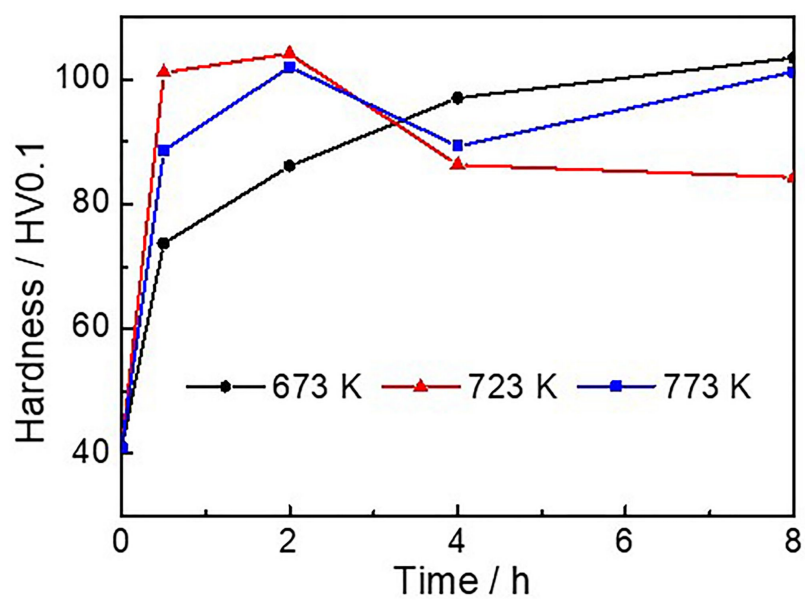

Figure 1: Comparisons of the micro-hardness of the $\mathrm{Cu}-0.52 \mathrm{Ag}$ $0.22 \mathrm{Cr}$ alloy after aging at different temperature for different time

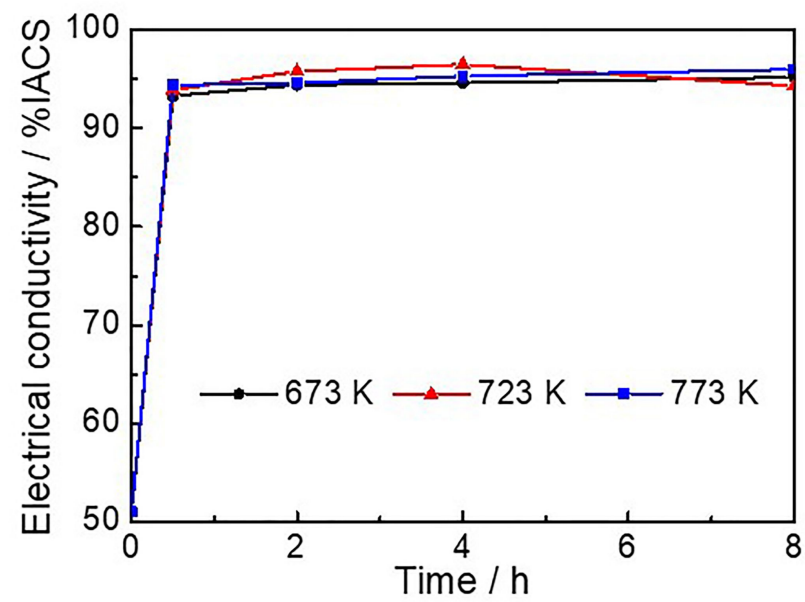

Figure 2: Variation of electrical conductivity with the aging time

enhanced after the aging process. As seen, after aging at $673 \mathrm{~K}, 723 \mathrm{~K}$, and $773 \mathrm{~K}$ for $30 \mathrm{~min}$, the micro-hardness of the alloys significantly increased to 73.7 HV0.1, 101.1 HV.01, and 88.6 HV0.1, respectively, which was 1.8, 2.5, 2.2 times that of alloy obtained after solid solution treatment.

Subsequently, micro-hardness continuously increased when the aging time prolonged to $2 \mathrm{~h}$. But the change trend was different under different temperature, when the aging time extended to $8 \mathrm{~h}$. Under relatively low temperature $(673 \mathrm{~K})$, one can observe the sustained growth of the micro-hardness to $103.5 \mathrm{HV} 0.1$ with the prolonged aging time to $8 \mathrm{~h}$. When the aging temperature was 723 $\mathrm{K}$ and $773 \mathrm{~K}$, the highest micro-hardness was 104.1 HV0.1 and 102.0HV0.1, both of which were obtained when the aging time was $2 \mathrm{~h}$.

Figure 2 shows the electrical conductivity of the alloys obtained after diverse aging temperatures for different times. Within a short period of $30 \mathrm{~min}$, there was an initial

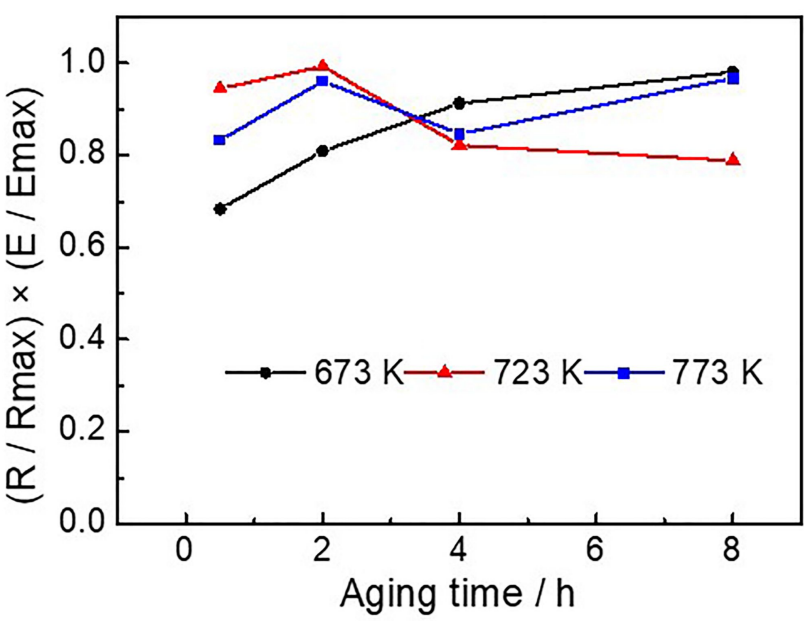

Figure 3: Standardized curves of micro-hardness and conductivity under different aging condition

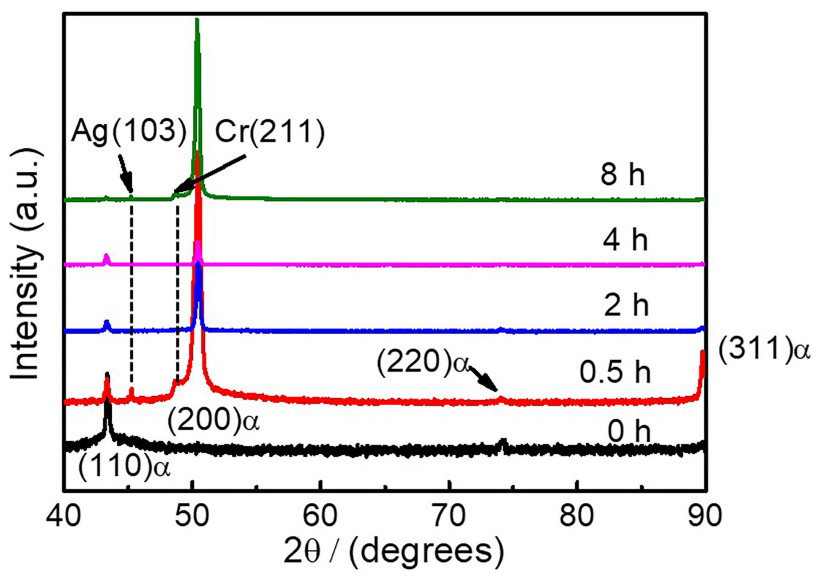

Figure 4: XRD pattern of the alloy at $723 \mathrm{~K}$ changes with time

burst increase for the electrical conductivity of the alloys, with electric conductivity of the 93.3, 93.9 and 94.4\% IACS after 30 min when the aging temperature was $673 \mathrm{~K}, 723 \mathrm{~K}$, and $773 \mathrm{~K}$, respectively. Compared to the initial electric conductivity of 51\% IACS, the electric conductivity increased $82.9 \%, 84.1 \%$, and $85.1 \%$. Then the electrical conductivity was almost unchanged when the aging time extended to 2, 4, 6 and $8 \mathrm{~h}$, respectively. So, the effect of temperature on electric conductivity is not very obvious. The maximum difference of electric conductivity reached 1.9\% IACS (96.5$94.6 \%$ IACS).

In practical applications, the alloys should be equipped with both excellent hardness and electrical conductivity at the same time. So we introduce a new formula $\left(\mathrm{R} / \mathrm{R}_{\max }\right) \times\left(\mathrm{E} / \mathrm{E}_{\max }\right)$, where $\mathrm{R}$ is the electric conductivity, $\mathrm{E}$ is the micro-hardness, and max is the maximum value. The obtained result was presented in Figure 3. When the aging process was performed under $723 \mathrm{~K}$ for $2 \mathrm{~h}$, the max- 

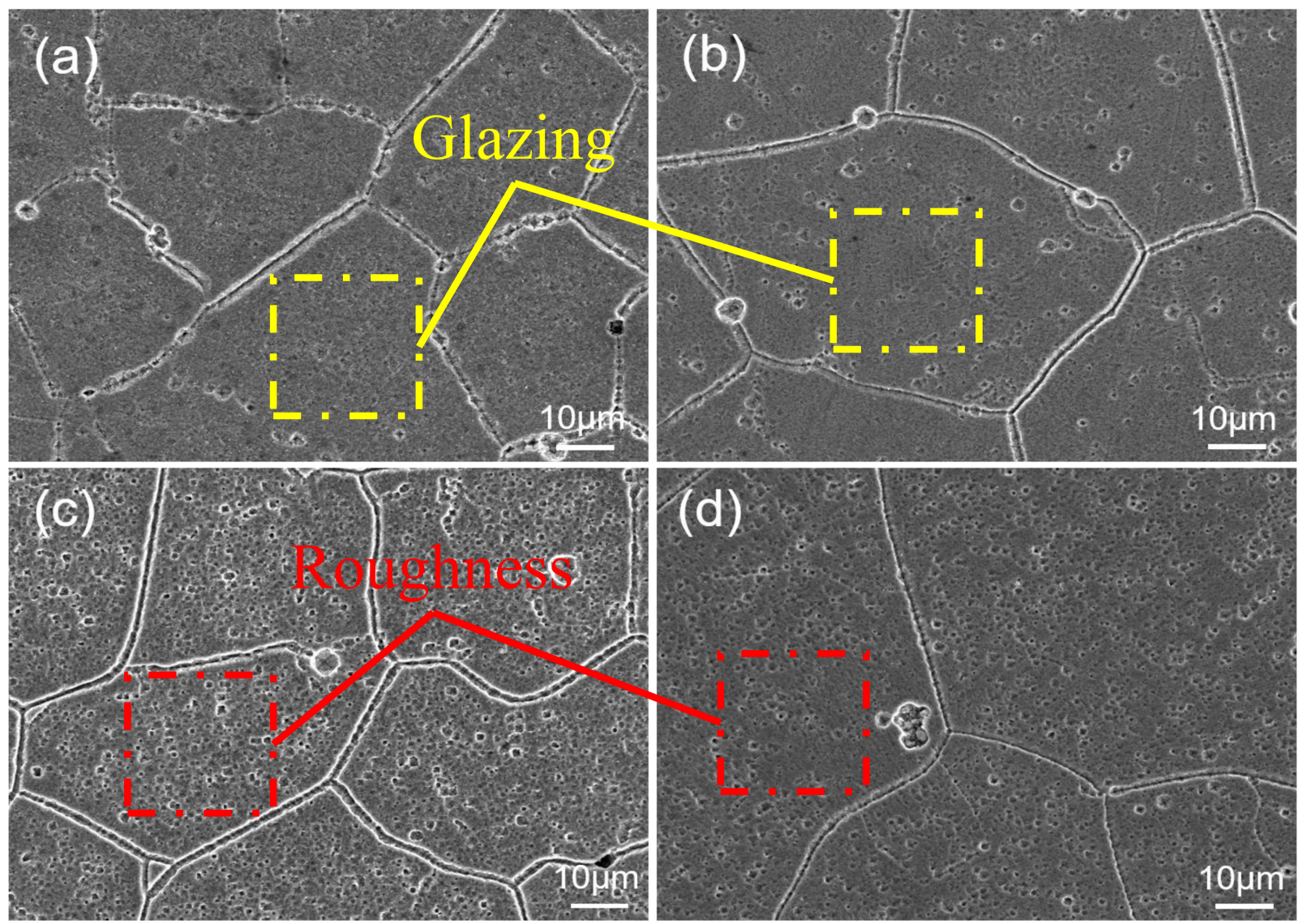

Figure 5: SEM images of the alloys obtained after aging at $723 \mathrm{~K}$ for different times: (a) $0.5 \mathrm{~h}$; (b) $2 \mathrm{~h}$; (c) $4 \mathrm{~h}$; (d) $8 \mathrm{~h}$
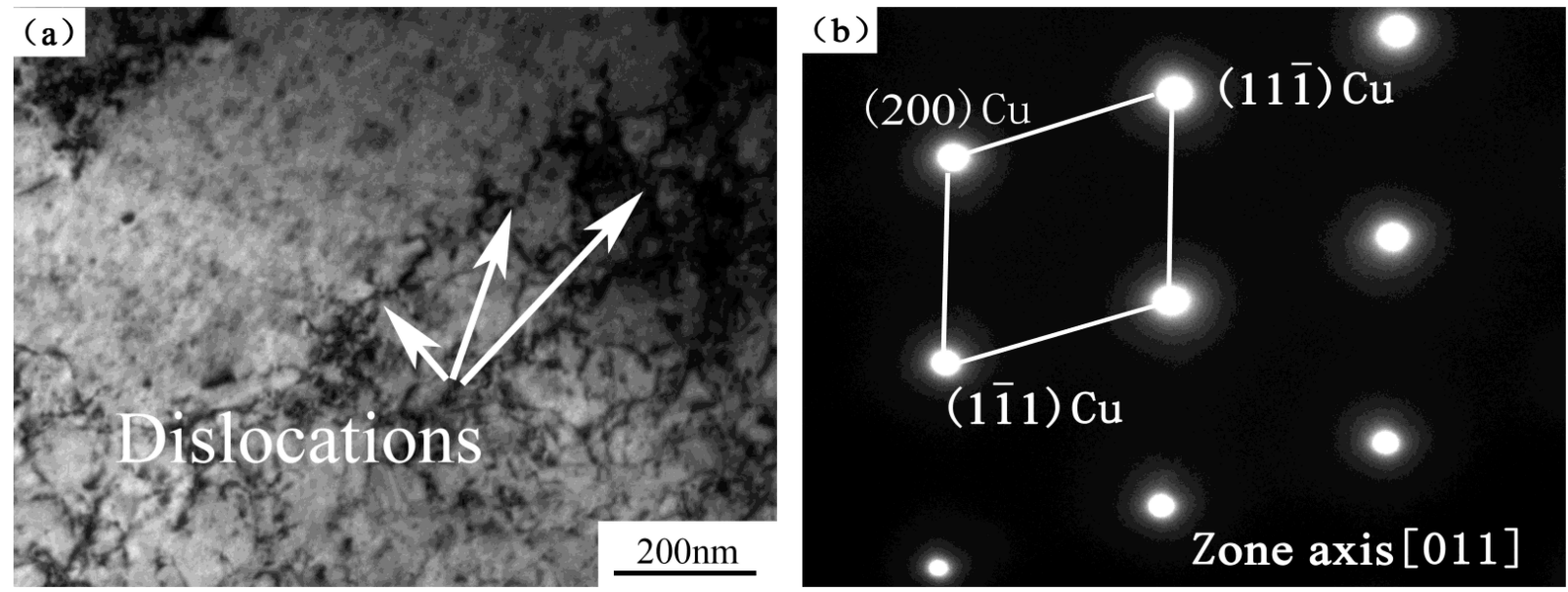

Figure 6: The TEM image for Cu-0.52 Ag-0.22 Cr alloy after solid solution: (a) bright field image; (b) SADE pattern

imum value is obtained. At this moment, the alloy has the best comprehensive properties (electrical conductivity and micro-hardness), with the electric conductivity of 95.8\% IACS and the micro-hardness of 104.1 HV0.1.

\subsection{Microstructure and nanoscale precipitates of alloy}

The properties of alloys are closely related to microstructure. Thus, the evolution of macroscopic phase was evaluated using XRD. Based on the XRD spectra in Figure 4, it is clear that the alloy with face-centered cubic crystal 


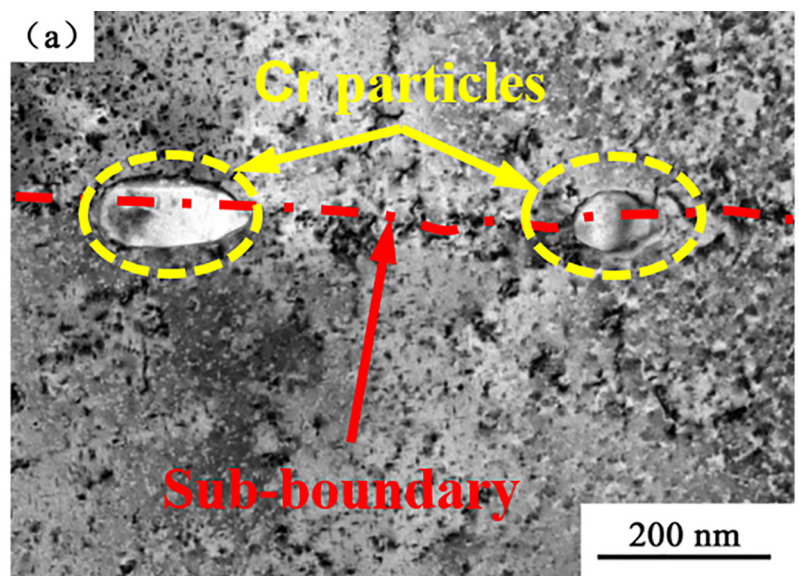

(b)
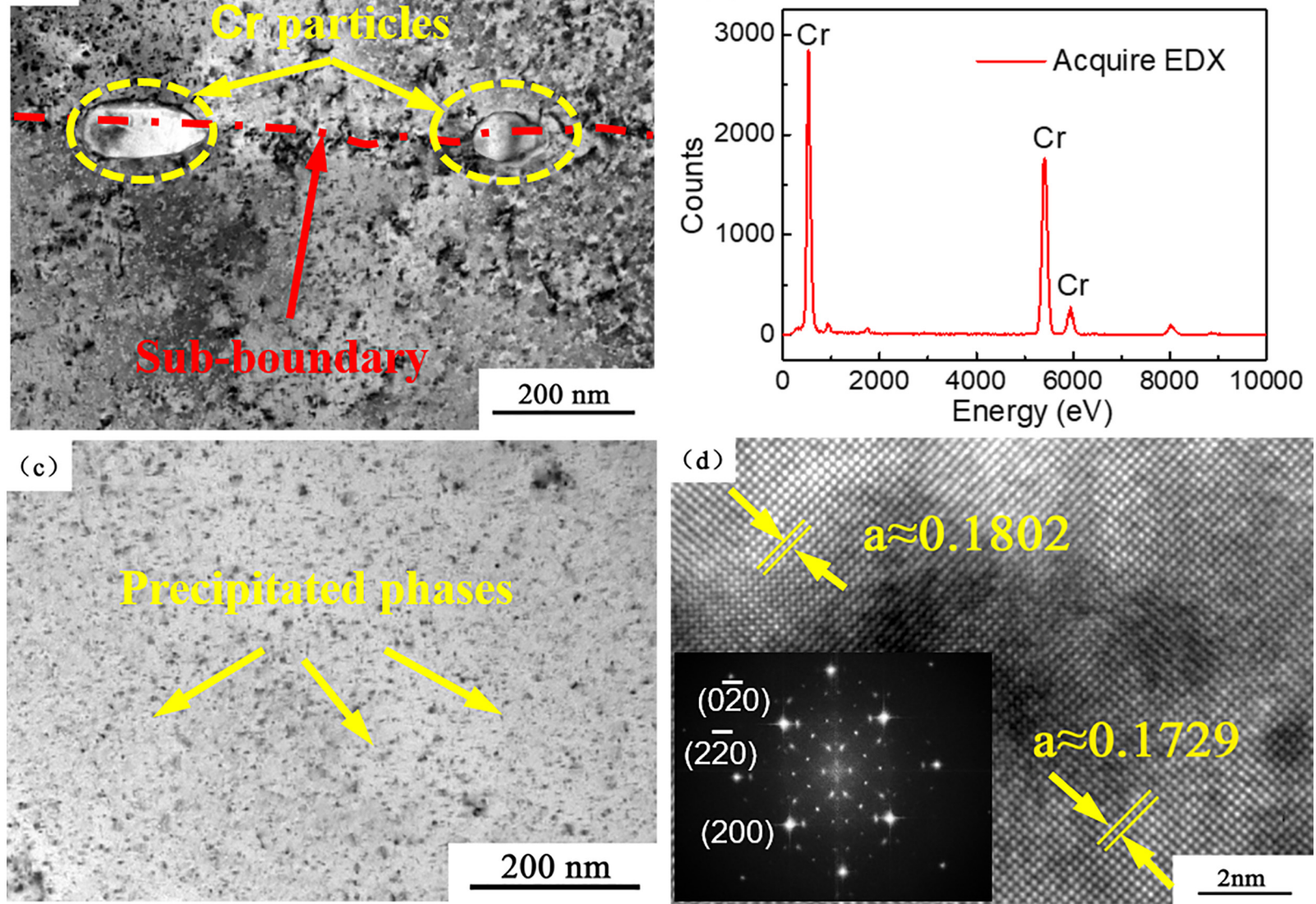

Figure 7: TEM images of the alloy at $723 \mathrm{~K} \times 0.5 \mathrm{~h}$ ( $\mathrm{a}$ and c) bright field image; (b) energy spectrum; (d) HRTEM

structure could be obtained after solid solution treatment at $1223 \mathrm{~K}$ for $1 \mathrm{~h}$, which was confirmed by the characteristic peaks of FCC-(110). As the sample was heated at $723 \mathrm{~K}$ for $0.5 \mathrm{~h}$, the FCC-(110) peak dramatically weakened. The XRD pattern was composed of the characteristic peaks of $\mathrm{Cu}$ (200), Cr (211) and Ag (103), indicating that Ag and $\mathrm{Cr}$ precipitated from the copper matrix and formed a new single phase. When the aging time continued, prolonged to 8 $\mathrm{h}$, the crystal phase of the alloys was almost unchanged, which was in agreement with the results presented in Figures 1 and 2. Under the aging temperature of $723 \mathrm{~K}$, the microstructure changed with the aging time and the results are shown in Figure 5. The microstructures of the alloys are all isometric crystals, and the grain surface gradually changed rough with the extension of aging time. Meanwhile, the grain grows with aging time. In order to further explore the occurrence of this situation, TEM was used to observe the nanoscale precipitates.

Figure 6a shows a typical transmission electron microscopy (TEM) image of the alloy obtained after solid solution. As seen, there are only dislocations in the TEM image and no precipitated phase can be observed. Only a set of diffraction patterns of the copper matrix can be seen from the Figure $6 \mathrm{~b}$.

Figure 7 shows the TEM images of alloy after aging at $723 \mathrm{~K}$ for $0.5 \mathrm{~h}$. A small number of elliptic particles with a size of about $100 \mathrm{~nm}$ can be seen from Figure 7 and most of them distributed on the sub-grain boundary. The EDX spectra in Figure 7b further confirmed that the main component of the particles was Cr. In addition, a large number of nanoscale precipitates with the size of 4-5 nm can be observed from the bright field image in Figure 7c. The lattice parameter of the copper matrix was 0.1729 , and the parameter of the precipitation phase is 0.1802 (Figure 7d). From the corresponding FFT diagram obtained by Fourier transform it can be found that the diffraction is relatively complex and the nanoscale precipitates and matrix are coherent. The phase relationship between the precipitated phase and the copper matrix can be expressed as $(\overline{1} 10) \alpha / /(1 \overline{1} 0) \gamma,[001] \alpha / /[001] \gamma(\alpha$ : copper matrix; $\gamma$ : $A g)$. Relatively to the solid solution state, a large number of dispersive $\mathrm{Ag}$ particles and $\mathrm{Cr}$ particles with large size were precipitated after $0.5 \mathrm{~h}$ of aging (Figure $7 \mathrm{c}$ and Figure $7 \mathrm{a}$ ). 

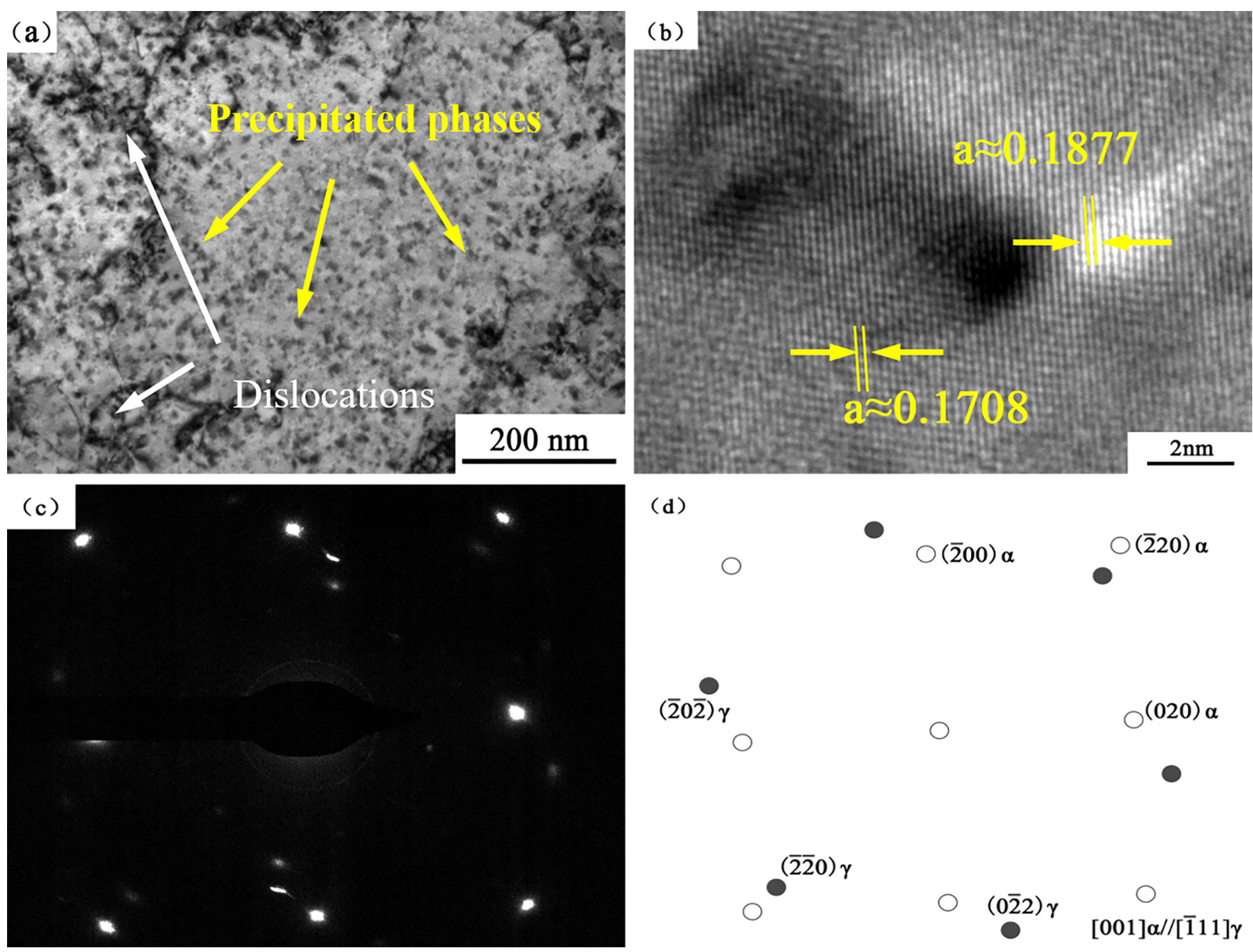

Figure 8: TEM of the alloy at $723 \mathrm{~K} \times 2 \mathrm{~h}$ : (a) bright field image; (b) HRTEM; (c) SADE pattern of the precipitate; (d) index of SADE pattern

The microstructure of product obtained after aging at $723 \mathrm{~K}$ for $2 \mathrm{~h}$ was shown in Figure 8a. The dimension of the nanoscale precipitates grew up to $8-10 \mathrm{~nm}$. The structure of the nanoscale precipitates did not change. It can be seen from Figure $8 \mathrm{~b}$ that the matrix parameters of copper matrix decreased and the matrix parameters of nanoscale precipitates increased. It revealed the growth of the precipitated phase and continuous precipitation. Through the calibration of the SADE and the calculation of the mismatch, the coherent relationship between the nanoscale precipitates and the matrix was lost. The phase relationship can be expressed as $(\overline{1} 10) \alpha / /(\overline{110}) \gamma$, [001] $\alpha / /[\overline{1} 11] \gamma$.

\section{Discussion}

\subsection{Effect of aging on properties of alloy}

The alloy kept steady supersaturated solid solution stage after solid solution treatment. Thus, the precipitation capacity of the second phase is large, and the precipitation rate is fast in the in the early stage of aging $[18,23]$, which leads to quick increase for the hardness of the alloys in the initial $30 \mathrm{~min}$. With the extension of aging time (30 min to $2 \mathrm{~h}$ ), the saturation gradually decreased, resulting the slow precipitation rate and the growth of precipitation phase [18]. This can affect the micro-hardness of the alloy, so the micro-hardness increases slowly. When the temperature is $673 \mathrm{~K}$, the diffusion rate for all elements in the alloy and the precipitation of the second phase is slow, causing unobvious strengthening effect [19]. When the temperature is $773 \mathrm{~K}$, the saturation of the alloy will be destroyed, and the precipitation power of the second phase will be insufficient. Moreover, the precipitated second phase will not stop growing. Thus, it can destroy the coherence phenomenon of the matrix, and the microhardness is inevitably declined when the aging time prolonged from 2 to $8 \mathrm{~h}[20,31]$.

The scattering effect of solid solution elements on electrons is the main reason that influences the electric conductivity of the alloys. The higher content of alloy elements in the matrix, the stronger the scattering effect 
on electrons, and the electric lower the conductivity of the alloy. Therefore, the electric conductivity and microhardness basically follow the same law. With the extension of time, the solid solution elements continuously precipitate and the matrix is closer to the copper matrix. The electric conductivity maintains at a high level. In the early stage of aging (before $0.5 \mathrm{~h}$ ), it has a higher saturation. As the result, the higher the temperature (less than $773 \mathrm{~K}$ ), the higher the electric conductivity is. In the later stage of aging, when the temperature is lower than $723 \mathrm{~K}$, the diffusion ability of solid solution elements decreases and the precipitation is slower [32,35]. When the temperature is higher than $723 \mathrm{~K}$, the saturation is low and the precipitation is slow. When the temperature is $723 \mathrm{~K}$, the precipitation is normal. The precipitation phase grows slowly with the extension of time, which will have a certain impact on the electric conductivity [35].

\subsection{Effect of nanoscale precipitates on properties}

After high-temperature solid solution treatment, it can be seen from both Figure 4 and Figure 6 that $\mathrm{Ag}$ and $\mathrm{Cr}$ are fully integrated into the copper matrix. Thus, the electric conductivity and microhardness of the alloy are relatively low. There are no nanoscale precipitates. After aging process, $\mathrm{Cr}$ accumulates in the sub-grain boundary in large nanoscale precipitates. It proves that the addition of Ag element can change the chain precipitation of $\mathrm{Cr}$ element [33]. It has a strong blocking effect on dislocation, as shown in Figure 8. The fine and dispersed Ag nanoscale precipitates gradually coarsened with the aging, and the phase connection with the matrix also changed. It can block the dislocation motion. The increase of electric conductivity is caused by the precipitation of $\mathrm{Ag}$ and $\mathrm{Cr}$ nanoscale precipitates from the copper matrix. The characteristic parameters of nanoscale precipitates have limited influence on the electric conductivity. Nevertheless, nanoscale precipitates have a significant effect on microhardness.

As it is well known, the strengthening mechanism of hardness is the nail-rolling effect on dislocation [34]. According to the calculated results of the mismatch degree, it can be concluded that the nanoscale precipitates and matrix are semi-coherent. At this point, through the study of the second phase strengthening mechanism (9.9\%), the Orowan strengthening mechanism can be adopted. The strengthening due to the Orowan model is described by the Orowan-Ashby equation [34]:

$$
\tau_{O A}=0.84 \frac{G b}{2 \pi(1-v)^{\frac{1}{2}} \alpha} \ln \left(\frac{\pi r}{2 \pi_{0}}\right)
$$

Where the $\tau_{0 A}$ is the shear stress of the Orowan-Ashby mechanism, $\mathrm{r}$ is the average radius of the Ag particle, $r_{0}$ is the dislocation center size, $\alpha$ is the hard particle spacing. In over-aging alloys, the Ag particle size will increase. While $\tau_{0 A}$ will reduce. Therefore, alloys will have lower micro-hardness. When dislocation cuts through the nanoscale precipitates [34]:

$$
\tau_{c}=2.6 G \epsilon^{\frac{3}{2}}\left(\frac{f}{\theta b}\right)^{\frac{1}{2}} r^{\frac{1}{2}}
$$

The relationship between $\alpha$ and the radius and volume fraction of the nanoscale precipitates can be calculated using the following equation [34]:

$$
\alpha=\left(\frac{2 \pi}{3 f}\right)^{\frac{1}{2}} r-\frac{\pi r}{2}
$$

Putting the relevant parameters into formula. ( $\mathrm{G}=$ 44.1MPa; $\mathrm{b}=0.2556 \mathrm{~nm} ; v=0.35 ; \theta=0.5 ; \epsilon=0.015 ; \mathrm{r}_{0}=$ 2b) Since the electric conductivity remains high level, we assume that $\mathrm{Ag}$ precipitates entirely from the copper matrix. According to alloy composition, the volume fraction of the precipitated phase was calculated to be $0.044 \%$. So, one can get the following formula:

$$
0.012 r^{\frac{1}{2}} \leq \frac{0.028}{r} \ln (3.07 r)
$$

Working out as $4<\mathrm{r}<5$. Therefore, when the aging time is prolonged, the nanoscale precipitates increases and the hardness decreases.

\section{Conclusion}

1. In the early stage of aging, the electric conductivity and micro-hardness increased significantly. With the extension of aging time, the electric conductivity remains at a high level and basically unchanged. While the micro-hardness increases slowly, the change trend is different at variuos temperatures. Therefore the micro-hardness is more sensitive to temperature than electric conductivity.

2. The optimum aging parameters are obtained within the experimental range. The best alloy can be obtained after aging at $723 \mathrm{~K}$ for $2 \mathrm{~h}$, with the microhardness of 104.1HV0.1 and electric conductivity of 95.8\% IACS.

3. The XRD result shows that the value changed greatly after aging. Only the diffraction front of copper matrix can be observed after solid solution. The peak of $\mathrm{Cu}$ (200), $\mathrm{Ag}$ (103) and $\mathrm{Cr}$ (211) are beginning to appear after aging. This means that $\mathrm{Ag}$ and $\mathrm{Cr}$ are precipitated from copper matrix. 
4. Nanometer precipitates have a significant effect on the improvement of alloy properties. In the aging process, $\mathrm{Cr}$ exists at the sub-boundary in the form of larger nanoscale precipitates (100-200 nm). At the same time, a large number of $\mathrm{Ag}$ particles dispersed on copper matrix. The size of $\mathrm{Ag}$ nanoscale precipitates is $8-10 \mathrm{~nm}$. The nanoscale precipitates are semi-congruent with the matrix. The phase relationship between the precipitated phase and the copper matrix can be expressed as $(\overline{1} 10) \alpha / /(\overline{11} 0) \gamma, \quad[001] \alpha / /[\overline{1} 11] \gamma$. The synergistic effect of $\mathrm{Ag}$ and $\mathrm{Cr}$ nanoscale precipitates greatly improved the properties of the alloy.

Acknowledgement: The present work is financially supported by the National key research and development program (2016YFB0301400), Henan innovation leading project (191110210400), Key scientific research projects of institutions of higher learning in Henan province (19A430012), and Innovation fund for outstanding talents of Henan province (182101510003).

\section{References}

[1] Horie H., Copper-titanium alloy for electronic component, U.S. Patent 10, 100, 387, 2018-10-16.

[2] Zhang X.H., Zhang Y., Tian B.H., Jia Y.L., Liu Y., Song K.X., Volinsky A.A., Xue H.H., $\mathrm{Cr}$ effects on the electrical contact properties of the Al203-Cu/15W composites, Nanotechnol. Rev., 2019, 8(1), 128-135.

[3] Yin Z.M., Zhang S.L., Hotspots and Developing Tendency on Highstrength and High-conductivity Copper Alloys, Min. Metall. Eng., 2002, 2.

[4] Rai M., Ingle A.P., Pandit R., Pandit R., Shende S., Gupta I., Biswas J.K., Silva S.S., Copper and copper nanoparticles: role in management of insect-pests and pathogenic microbes, Nanotechnol. Rev., 2018, 7(4), 303-315.

[5] Okafuji Y., Copper-cobalt-silicon alloy for electrode material, U.S. Patent 10, 056, 166, 2018-8-21.

[6] Scott A., Vadalasetty K.P., Chwalibog A., Sawosz E., Copper nanoparticles as an alternative feed additive in poultry diet: a review, Nanotechnol. Rev., 2018, 7(1), 69-93.

[7] Liu Y., Liu P., Li W., Tian B.H., Aging behavior and electrical sliding wear properties of $\mathrm{Cu}-\mathrm{Cr}$-Zr-Ce alloy,Trlbol. Int., 2005, 25(3), 265 269.

[8] Ban I., Stergar J., Maver U., NiCu magnetic nanoparticles: review of synthesis methods, surface functionalization approaches, and biomedical applications, Nanotechnol. Rev., 2018, 7(2), 187-207.

[9] Bracey C.L., Ellis P.R., Hutchings G.J., ChemInform Abstract: Application of Copper-Gold Alloys in Catalysis: Current Status and Future Perspectives, Chem. Soc. Rev., 2009, 38(8), 2231-2243.

[10] Zuo X., Qu L., Zhao C., An B., Wang E., Niu R., Xin Y., Lu J., Han K., Nucleation and growth of $\gamma$-Fe precipitate in $\mathrm{Cu}-2 \% \mathrm{Fe}$ alloy aged under high magnetic field, J. All. Compd., 2016, 662, 355-360.
[11] Prokoshkina D., Esin V.A., Divinski S.V., Experimental evidence for anomalous grain boundary diffusion of $\mathrm{Fe}$ in $\mathrm{Cu}$ and $\mathrm{Cu}-\mathrm{Fe}$ alloys, Acta Mater., 2017, 133, 240-246.

[12] Guo F., Wang C., Cheng D., Current Status and Development Trend of Rolling Technology of Copper Alloy Plate and Strip, Hot Work. Tec., 2016, 19, 10-13.

[13] Krishna S.C., Abhay K., Properties and Strengthening Mechanisms in Cold-Rolled and Aged Cu-3Ag-0.5Zr Alloy, Metall. Microst. An., 2014, 3(4), 323-327.

[14] Zhou Y.J., Song K.X., Xing J.D., Zhang Y.M., Precipitation behavior and properties of aged Cu-0.23 Be-0.84 Co alloy, J. All. Compd., 2016, 658, 920-930.

[15] Mishnev R., Shakhova I., Belyakov A., Kaibyshev R., Deformation microstructures, strengthening mechanisms, and electrical conductivity in a Cu-Cr-Zr alloy, Mat. Sci. Eng. A - Struct., 2015, 629, 29-40.

[16] Jia S.G., Liu P., Tian B.H., Zheng M.S., Zhou G.S., Lou H.F., Strengthening mechanism in high-strength and highconductivity $\mathrm{Cu}-0.1 \mathrm{Ag}-0.11 \mathrm{Cr}$ alloy, China J. Nonferrous, 2004, 14(7), 1144-1148.

[17] Li R.G., Kang H.J., Chen Z.G., Fan G.H., Zou C.L., Wang W., Zhang S.J., Lu Y.P., Jie J.C., Cao Z.Q., Li T.J., A promising structure for fabricating high strength and high electrical conductivity copper alloys, Sci. Rep., 2016, 6, 20799.

[18] Li H.W., Dai J.Y., Strengthen mechanism and ration analysis of Cu-Ag-Cr alloy, China J. Rare Metals, 2010, 34(6), 828-832.

[19] Wang M.H., Huang L., Chen M.L., Wang Y.L., Processing map and hot working mechanisms of $\mathrm{Cu}-\mathrm{Ag}$ alloy in hot compression process, J. Cent. South Univ., 2015, 22(3), 821-828.

[20] Gubicza J., Sitarama R.K., Subramanya S.V., Alexander K., Zoltan H., Martin P., The Effect of Thermomechanical Treatment on the Microstructure and the Mechanical Behavior of a Supersaturated Cu-Ag Alloy, Mater. Sci. Forum, 2015, 812, 6.

[21] Du D., Fautrelle Y., Dong A., Shu D., Zhu G., Sun B., Effect of Ag Content on the Microstructure and Crystallization of Coupled Eutectic Growth in Directionally Solidified Al-Cu-Ag Alloys, Metall. Mater. Trans. A, 2018, 49(10), 4735-4747.

[22] Wang S., Zhang Y., Yao D., Micro-structure and Properties of Cu0.3 wt\% Ag Alloy Ultra-Fine Wires, TMS 2019 148th Annual Meeting and Exhibition Supplemental Proc. Springer, Cham, 2019, 629-635.

[23] Kim S.W., Wang Y., Jung T.K., Jin C.Y., Choung J., Lee J.W., Pore Characteristics of Lotus-Type Porous $\mathrm{Cu}-\mathrm{Fe}$ and $\mathrm{Cu}-\mathrm{Cr}$ Alloys Fabricated by Unidirectional Solidification, J. Nanosci. Nanotechnol., 2018, 18(3), 2262-2265.

[24] Tian W., Bi L., Ma F., Du J., Effect of Zr on as-cast microstructure and properties of Cu-Cr alloy, Vacuum, 2018, 149, 238-247.

[25] Feng X., Xie H., Li Z., Mi X., Huang G., Peng L., et al, Comparison of $\mathrm{Ag}$ and $\mathrm{Zr}$ with same atomic ratio in $\mathrm{Cu}-\mathrm{Cr}$ alloy, IOP Conf. Series: Mat. Sci. Eng. IOP Pub., 2018, 397(1), 012053.

[26] Su J.H., Dong Q.M., Liu P., LI H.J., Kang B.X., Aging hardening and recrystallization of the deformed $\mathrm{Cu}-0.3 \mathrm{Cr}-0.15 \mathrm{Zr}-0.05 \mathrm{Mg}$ alloy, Heat Treat. Met. C, 2004, 29(2).

[27] Gubicza J., Hegedűs Z., Lábár J.L., Kauffmann A., Freudenberger J., Subramanya S.V., Solute redistribution during annealing of a cold rolled Cu-Ag alloy, J. All. Compd., 2015, 623, 96-103.

[28] Li W.B., Pan Q.L., Xiao Y.P., He T.B., Liu X.Y., Effect of aging processes on microstructure and properties of Al-Zn-Cu-Mg-Sc-Zr alloy, T. Mater. Heat Treat., 2011, 32(8), 47-53. 
[29] Jia S.G., Zheng M.S., Liu P., Ren F.Z., Tian B.H., Zhou G.S., Lou H.F., Aging properties studies in a Cu-Ag-Cr Alloy, Mat. Sci. Eng. A - Struct., 2006, 419(1-2), 8-11.

[30] Liu J.B., Zhang L., Meng L., Effects of rare-earth additions on the microstructure and strength of $\mathrm{Cu}-\mathrm{Ag}$ composites, Mat. Sci. Eng. A - Struct., 2008, 498(1-2), 392-396.

[31] Chen H.M., Yuan D.W., Wu S.J., Wang H., Xie W.B., Yang B., Relationship between Microstructure and Properties of Cu-Cr-Ag-(Ce) Alloy Using Microscopic Investigation, Scanning, 2017, 2017, 1-8.

[32] Xu S., Fu H., Wang Y., Xie J.X., Effect of Ag addition on the microstructure and mechanical properties of $\mathrm{Cu}-\mathrm{Cr}$ alloy, Mat. Sci. Eng. A - Struct., 2018, 726, 508-214.
[33] Liu Y., Li Z., Jiang Y.X., Zhang Y., Zhou Z.Z., Lei Q., The microstructure evolution and properties of a $\mathrm{Cu}-\mathrm{Cr}-\mathrm{Ag}$ alloy during thermalmechanical treatment, Mater. Res., 2017, 32, 1324-1332.

[34] Correia J.B., Davies H.A., Sellars C.M., Strengthening in rapidly solidified age hardened $\mathrm{Cu}-\mathrm{Cr}$ and $\mathrm{Cu}-\mathrm{Cr}$-Zr alloys, J. Acta Mater., 1997, 45(1), 177-190.

[35] Bao G., Xu Y., Huang L., Lu X., Zhang L., Fang Y., Strengthening Effect of Ag Precipitates in Cu-Ag Alloys: A Quantitative Approach, Mater. Res. Lett., 2016, 4(1), 37-42. 